\title{
Threshold concepts: designing a format for the flipped classroom as an active learning technique for crossing the threshold
}

\author{
Nkaepe E. E. Olaniyi(i)
}

\author{
Correspondence: nkaepe.olaniy@ \\ kaplan.com \\ Kaplan Open Learning, 6 Grace St, \\ Leeds LS1 2RP, UK
}

\begin{abstract}
There is so-called troublesome knowledge in every subject. There is various subjectspecific research available on what these particular concepts are, as well as some examples of how to help students cross those thresholds. There is, however, a gap in the area of implementation, a more practical format for addressing student learning when there are threshold concepts. As active learning encourages deep learning, this is key to any pedagogical method used. There is a need for a mix of teaching approaches to address the diverse learning styles that exist in any class. This paper seeks to provide a viable format that can be applied to any subject. This format is based on a flipped lesson in physics (in a higher education context) and the results from three cohorts across two academic years. The paper highlights the need for meta-learning when dealing with threshold concepts, as well as the use of interactive videos as a practical tool that contributes to self-efficacy.
\end{abstract}

Keywords: Troublesome knowledge, Interactive videos, Action research, Studentcentred learning, Technology-enhanced learning

\section{Introduction}

A threshold concept refers to core concepts in a subject where understanding these concepts is key to transforming the way students understand a whole subject, allowing them to move on in their learning (Cousin, 2006; Meyer \& Land, 2003). This means that a student will have to enter a liminal state in their thinking, in order to understand the core concept (Cousin, 2006; Meyer \& Land, 2003).

A threshold concept can be described as transformative (a significant shift in understanding), probably irreversible (difficult to unlearn), integrative (reveals the association between various topics), sometimes bounded (specific to a particular discipline), and potentially troublesome (difficult to grasp, counter-intuitive) (Flanagan, 2017; Meyer \& Land, 2003).

Recent research has highlighted common topics in various subjects that are threshold concepts/troublesome knowledge for students. Some examples have already been analysed explicitly in the literature, covering a variety of disciplines. In economics, the concept of opportunity cost has been identified as a concept that is difficult to learn (O’Donnell, 2015). In business, certain aspects of business finance have been identified as threshold concepts (Bajada, Jarvis, Trayler, \& Bui, 2016). Photosynthesis and

(C) The Author(s). 2020 Open Access This article is distributed under the terms of the Creative Commons Attribution 4.0 International License (http://creativecommons.org/licenses/by/4.0/), which permits unrestricted use, distribution, and reproduction in any medium, provided you give appropriate credit to the original author(s) and the source, provide a link to the Creative Commons license, and indicate if changes were made. 
enthalpy have been researched in this context of threshold concepts in biology (Kinchin, 2010) and chemistry (Chandler-Grevatt, 2015), respectively. In mathematics, the topic of complex numbers is known to be difficult to grasp by many students (Meyer \& Land, 2003). In physics, there are several concepts that fall into the category of being counter-intuitive, and even transformative in nature (Serbanescu, 2017).

Overcoming threshold concepts/troublesome knowledge is an uncomfortable process as familiar ways of thinking. The security attached to that must be lost in order for new knowledge to be accepted (Rhem, 2013). Rhem (Rhem, 2013) stated that self-efficacy is very much a requirement in helping students understand threshold concepts. This is because it places the student in a psychological frame of mind needed to overcome the threshold concept.

Meyer and Land (Meyer \& Land, 2006) provided the following guidelines for course design in order to overcome threshold concepts/troublesome knowledge. Firstly, there is a need for engagement by students. The students need to be able to explain the concept, represent it in new ways, and connect it to their lives. Being able to explain the concepts in their own words means it is understood or the process of change in their thinking has begun.

The second element is the need for peer assessment. This is necessary to help students discover difficulties and anxieties they share with their peers. This helps students to cross that liminal space, knowing they are not alone in this learning process.

Finally, there is a need for both a recursive approach (having different "takes" with the material available) and an excursive approach (being on a learning journey with an outcome that has allowances for diversions). Students should be able to go back to the learning material at times which suit them so that the learning process can continue. In that process, there has to be room for mistakes to be made and lessons learned.

The question then arises-what methods can be used to help students overcome the threshold? This is the question which underlies this study. It is widely accepted that active learning is a viable method for helping students understand a topic. Various disciplines regularly apply various forms of active learning (Biggs \& Tang, 2011; Clarke, 2010; Meyer \& Land, 2006; Mezirow, 1991). This usually involves, but is not limited to, class polls/clickers, quizzes, group discussions, and game-based learning (Schmidt, Wagener, Smeets, Keemink, \& van der Molen, 2015).

In determining how to apply active learning techniques to the teaching of a threshold concept, there is still the need to allow time for the recursive and excursive approaches mentioned by Meyer and Land (Meyer \& Land, 2006), as well as promoting selfefficacy as stated by Rhem (Rhem, 2013). Flipped learning is a pedagogical approach covering all these guidelines. It incorporates active learning techniques in its delivery. Furthermore, it has recently been identified as a learning technique that helps students understand a wide range of topics (Bates \& Galloway, 2012; Danker, 2015; Hwang, Lai, \& Wang, 2015). In addition, using various modes of delivery during a flipped lesson enables an educator to address the various learning styles within a class.

There is limited research that specifically reviews flipped learning as an active learning tool to help students understand threshold concepts. Hence, the aim of this paper is to shed new light on this aspect of flipped learning, as well as to provide a practical approach for academics seeking to use flipped learning as a tool to help students understand a threshold concept. 


\section{Theoretical background}

Flipped learning (or flipped classrooms) refers to a pedagogical model where the typical lecture and homework elements of a course are reversed (Khoo, Peter, Scott, \& Round, 2018). Bergmann and Sams (Bergmann \& Sams, 2012) were some of the early pioneers of the flipped classroom. They started their experiment into this pedagogical approach by recording lessons for students who were absent from their classes. Bergmann and Sams then discovered that students who did not miss the classes were watching the videos. As a result, there was more student interaction in class. Help could be directed to students who needed it. This active engagement by students during flipped lessons is regularly cited in the literature that discusses this pedagogical approach (Hung, 2015; Nouri, 2016).

Bergmann and Sams (Bergmann \& Sams, 2012) sum up flipped learning and its link to active learning in their definition of a flipped classroom, "...a dynamic, interactive learning environment where the educator guides students as they apply the concepts and engage creatively in the subject matter": Flipped learning currently is used in higher education as a way of incorporating student-centred learning (and active learning) into the syllabus (Khoo et al., 2018; University of Plymouth, 2014).

Even with the positives of the flipped lesson, there are voices of concern (Sun, 2017), involving teacher workload and student motivation. These need to be considered when designing the flipped classroom, as there are various ways of overcoming these challenges (Moffett, 2015; University of Toronto, 2019).

Hwang et al. (Hwang et al., 2015) succinctly described the general components of a flipped lesson, covering the various learning levels as described by Bloom's taxonomy (Anderson et al., 2001). The lesson should involve the provision of the relevant teaching materials before the lesson for students to learn outside the classroom. This means that the tools must be electronic in nature and available online so they can be accessed anywhere. This process of self-learning encourages remembering and understanding. This can (and should) include some form of self-assessment. Essentially, the time used at home to do homework is now moved to the class time. Therefore, in class, the emphasis is on peer interaction, student-teacher interaction, and problem-solving skills (applying, analysing, and evaluating). Milman (Milman, 2012) stated using flipped learning for teaching conceptual knowledge would require "more time and thought", including scaffolding activities that can be utilised by all types of learners.

Hence, creating such a lesson should cover the key requirements for overcoming a threshold concept (Meyer \& Land, 2006). In terms of engagement, the students are continuously engaged with the topic as they prepare (remember and understand) for the lesson at home, rather than coming into the lesson to be taught for the first time. Peer assessment is a key part of the lesson, which usually takes place in class sessions. To establish a better understanding of the topic, the students can work with their peers. Sharing common anxieties or even gaining a different perspective can make this an enjoyable lesson/learning journey for the students.

Recursive and excursive approaches are applied throughout the student's learning journey (Sun, 2017). The student can take their time to go over the material, rather than feeling rushed during a standard teaching/lecturing session. The availability of the material online means this can be done using an approach that suits the student.

Meta-learning is also encouraged when flipped learning is used. This refers to the use of learning processes that focus students' attention on their own learning (via self- 
assessment) and that of their peers (via peer-assessment) in a given context (Timmermans \& Meyer, 2017). This can be achieved with online tests and quizzes, as well as interactive videos. Improvements in meta-learning have been linked to improvements in self-efficacy (Bialik \& Fadel, 2015).

Interactive videos are a recent addition to flipped learning. They allow students to actively engage with the material being taught, rather than passively watching it (Milman, 2012). These videos contain embedded interactive activities (such as quizzes and open questions) in order to gain a level of engagement from students (Galster, Mitrovic, \& Gordon, 2018). Various research has shown that an interactive video is a powerful tool in the learning process, encouraging reflection and student-directed learning (Galster et al., 2018; Jisc, 2010; Langbauer \& Lehner, 2015). Hence, meta-learning and selfefficacy in students are encouraged by the use of these videos.

Based on the review of previous research, this action research piece was developed to explore the use of flipped learning on a common threshold concept encountered by physics students. I decided to take this approach as it would allow me to consider the implications of changes to my teaching in an informed manner before finalising those changes. I would be able to review the students' perspective on the use of the flipped classroom, as well as their final grades, to determine the impact of the lesson structure. This paper will introduce e-learning technologies I used over a 2-year period. The flipped learning format proposed here is designed to be a starting point for any academic. It is liable to adaptation primarily based on the concept being taught, as well as the students enrolled on the module/course.

\section{Methodology and results}

Methodological approach

The methodological approach underpinning this research is an action research. Action research is commonly used to determine the impact of the flipped learning pedagogy at various levels of education (Guvenc, 2018; Kouloumbaritsi, Dimitroglou, Mavrikaki, \& Galanopoulou, 2013; Sun, 2017). Descombe (2014) described action research as a "hands-on, small scale research project". It sets out to "not only gain a better understanding of the problems which arise in everyday practice but actually to alter things".

In action research, once a practical issue has been identified, plans are made to rectify the issues, then put into action. Then, these actions are put through a systematic process of observation, reflection, and change (Kouloumbaritsi et al., 2013). The objective of the action research is improvement. This should be visible in three areas: practice (via the actions taken), understanding of practice, and the situation in which the practice takes place (Kouloumbaritsi et al., 2013).

Action research is cyclical in nature, as feedback from findings should inform further research. Indeed, this addresses the aim of being able to consider implications, by reflecting on my teaching practice, before making any significant changes to my delivery methods. A second crucial aspect of action research is active participation in the research, with participants working in partnership with the practitioner to help determine a viable solution to the research question (Descombe, 2014). Hence, this research method is the optimal means of determining students' perspective of the flipped classroom as their participation must be active, not passive. 
The research described here involved the use of surveys and a review of end of term results for the students in the study. The research was carried out over two academic years with adjustments made to the lesson outline based on feedback from the previous cohorts. The questions used in the survey were multiple choice with options ranging from "strongly agree" to "strongly disagree". The multiple-choice questions covered various aspects of the flipped lesson structure and individual activities. There was an area for open comments. The surveys were delivered at various times in the year for each cohort in order to gain a better understanding of the student learning journey while using this lesson structure.

Before commencement, the research was discussed with, and agreed upon by, my organisation and each cohort. The data gathered was anonymised and stored securely, with exam results being stored on the organisation's secure systems.

The following description of the research design and results follows the format for an action research piece. These are: identifying the research question (as stated in the "Introduction" and in the "Case description" sections), formulating a research plan (in this case, a flipped lesson), systematically collecting data (via class observations and end of term exam results), analysing the data, evaluating, and reporting on the data to inform subsequent changes (Guvenc, 2018).

\section{Case description}

The threshold concept on which this study focuses is thermodynamics. This topic is part of a first semester physics module on a foundation year science programme, taught at UK Qualifications and Credit Framework Level 3 (equivalent to UK A Levels). The programme admits two cohorts of students in any academic year, in September and January.

Thermodynamics was a topic that all students had difficulty understanding and applying. Having taught the subject for just over 2 years, I decided a change in strategy was necessary. It was during my PGCert (HE) course that I later realised I was dealing with a threshold concept. Even with $3 \mathrm{~h}$ a week and three consecutive teaching weeks dedicated to the topic, there never seemed to be enough time to ensure the students grasped the core concepts of thermodynamics.

Reviewing Bloom's taxonomy, I was able to identify key learning goals for my students: show understanding then apply their knowledge to different scenarios, as well as provide some essential analysis (Anderson et al., 2001). Given the topic, I realised that getting students to the higher-order learning skills would require some time and careful planning on my part. That was when I identified flipped learning as a means to help me help my students. So, this approach was applied in the academic years 2016/2017 (January cohort of 26 students) and 2017/2018 (September cohort of 45 students and January cohort of 27 students).

\section{6/2017 academic year research design}

I planned my first thermodynamics flipped classroom for the January 2016/2017 cohort. I already had lecture notes and slides prepared for the topic, as well as websites that could be used for further research and self-assessment. I then had to create interactive videos. I used two videos, both taken from YouTube, each one lasting no more 
than 10 min (University of Plymouth, 2014). I used the online web application H5P to insert questions at various points in the videos, prompting students to show some understanding/prove attention was being given to the video content before moving on with the video (Galster et al., 2018; Mayer, 2014).

My first lesson with the cohort was the week before the Easter holidays. I made this an introductory lesson. The concept of a flipped lesson was explained, as well as some of the key concepts in the topic. The resources were made available to the students via the Blackboard module area. Over the 2-week holiday, the students were required to work through the materials, including lesson notes, external websites, standard videos, and interactive videos; and a self-assessed online test. I sent announcements to the students once a week to remind them of the activity that should be undertaken before the end of that week (Kirschner, Sweller, \& Clark, 2015). This was especially important for the online test, as I did not make that available until the second week.

On their return, the students undertook 3 more teaching sessions. These were purely seminar sessions. During the first seminar session, I found only a handful of students had not watched the videos nor read any of the materials (5 students out of a class of 26). Hence, I ensured there were mixed groups in the session, with at least 1 person in the group who had not accessed the learning materials.

The questions provided were all past exam questions, covering both theory/explanation and calculation questions. I took on the "guide on the side" role (King, 1993), walking around the groups to ensure that everyone was participating.

During the activities, I noticed good evidence of self-directed learning as most students had hand-written notes they used to discuss their answers. There were a few general questions, but I did not need to give a lecture. In fact, there was an increased interaction between the groups; leading to large-scale discussions, my role was to provide clarity as to why some answers were less intuitive. Those students who had not prepared for the lessons did feel some form of peer pressure and did their best to contribute to the session. By the second seminar session, there was a turnaround with these five students. They brought in hand-written notes and contributed more frequently to the discussions.

\section{6/2017 academic year results}

To gauge student opinions on the use of the flipped lesson, I gave the survey in the second semester, after the students had received their first semester results. Figure 1 shows that most of them strongly agreed that the flipped lesson helped them learn. Therefore, it was clear that the lesson, though challenging, was enjoyable, with many students mentioning that they loved learning at their own pace.

Common suggestions for improvement were for more videos, as well as more questions to test learning. Regarding the aspects they enjoyed, the students mentioned that they enjoyed taking responsibility for their own learning; being able to learn in their own time and at their own pace. This is a clear indication that meta-learning, and hence self-efficacy, is taking place, with students becoming more independent and confident in their learning journey.

The final test to determine how well the students performed on this topic was in the exam. For past cohorts, questions on this topic have received the lowest scores from most students; even those who scored highly in the exam would gain only a few marks 


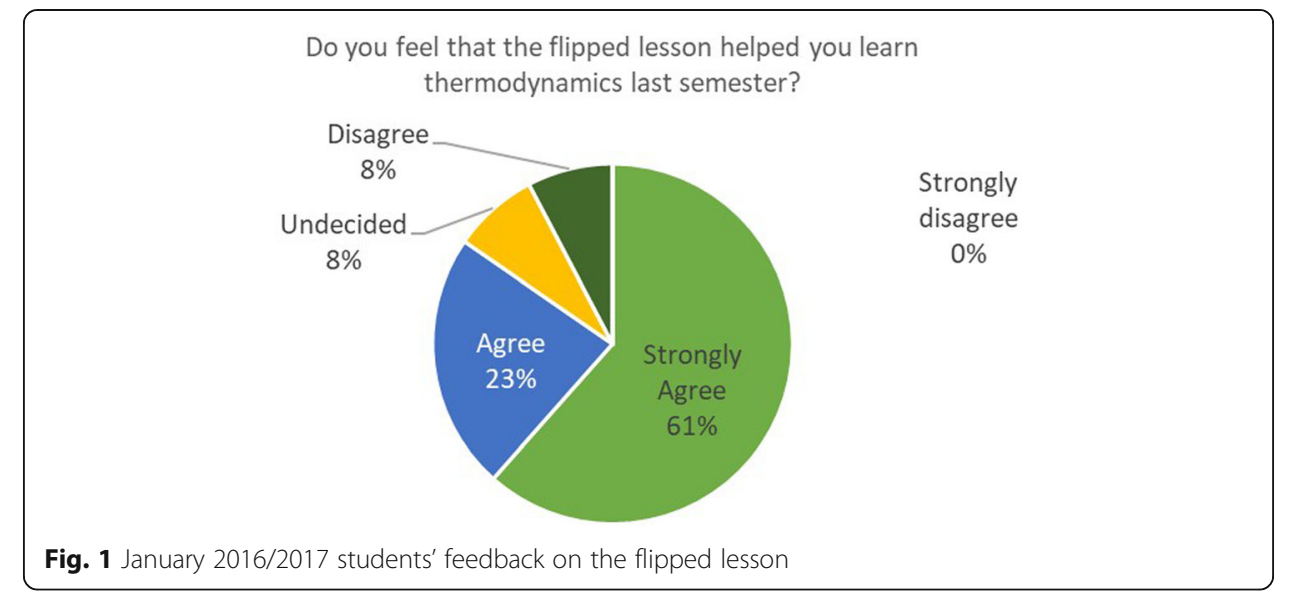

in this section. For example, only half of the 40 students from the September 2016/ 2017 cohort attempted the 3 questions on this topic with most gaining fewer than half marks. For the January 2016/2017 cohort, there were 2 questions on this topic. Nineteen out of the 26 students passed the exam (scored above 40\%). Out of the 19, only 5 did not attempt the 2 questions or failed to receive any marks in this section. So, over $70 \%$ of the students, who passed, scored highly in this topic, proving the session was a success. These exam results are in line with research, which has seen a boost in examinations scores and lower failure rates where flipped learning has been used (Freeman et al., 2014; University of Plymouth, 2014).

\section{7/2018 academic year research design}

Based on the success of the previous academic year, I decided to continue to use the flipped learning structure in the new academic year. Limited time meant I would have to use it for the thermodynamics lessons only. As most of the material was already available, I merely had to review the structure.

One piece of feedback from the previous year was for a better guidance on key learning aims for the topic-what exactly were they supposed to learn/understand? Based on this, I decided to change the format-I would provide the students with more questions to help them evaluate their own learning. I put this in the form of guide questions, which covered the learning outcomes for the topic and would be used for class discussions.

Therefore, in the first session, I provided a summary of the format of the flipped classroom and key aspects of the topic. With a new teaching structure of two 1.5-h sessions a week for 3 weeks, the first session of each week was used to cover the guide questions while the second session was for the seminars.

The students were required to study the lesson notes, website links, and videos at home. I sent announcements to remind them of the work to be done before class, as well as when the online test was available. In class, the guide questions were displayed and the students provided answers using the Q\&A section of the polling app Vevox (formerly known as Meetoo). I acted as a moderator and projected answers (both correct and selected incorrect answers) on the board to enable discussion/clarification. At the end of each session, I made the transcript of the Vevox questions and answers 
available online to remind the students of the class discussions. The second session enabled the students to apply their knowledge to past exam questions.

In the first guide session, most students in both cohorts did come to the session prepared. Those who were not prepared used the "thinking time" during the session to look up answers using the lesson notes and the other materials provided. Some of them were keen to ask questions and contribute to the discussion. Again, I believe "peer pressure" played a part in the change of approach as subsequent sessions saw all students actively taking part, with a preference for the seminar session.

\section{7/2018 academic year results}

In terms of feedback, the same questions were posed to the students, with a section that included their thoughts on the guide questions. In order to gain some insight into their learning journey, I delivered the surveys at different times in the semester. The September cohort provided feedback after their end-of-semester exam but before the results were released. The January cohort provided feedback a week after the flipped lessons had ended. Figures 2, 3, and 4 highlight the students' perception of the sessions.

The figures show that it is necessary to make the students aware of the learning journey for them to appreciate the progress they are making. Both cohorts clearly found the guide questions useful to their learning, as conveyed in Fig. 2. Similar results for both 2017/2018 cohorts meant an average for the whole year could be taken in the survey results.

It seems (as can be expected) that waiting for the final exam results may cause doubts in students' minds: have they done enough to pass? The final exam results for the September 2017/2018 cohort proved that there was no cause for concern. The feedback also showed that students also wanted more videos and practice questions. Both groups commented on the need for a brief explanation before the session so they could understand the topic better.

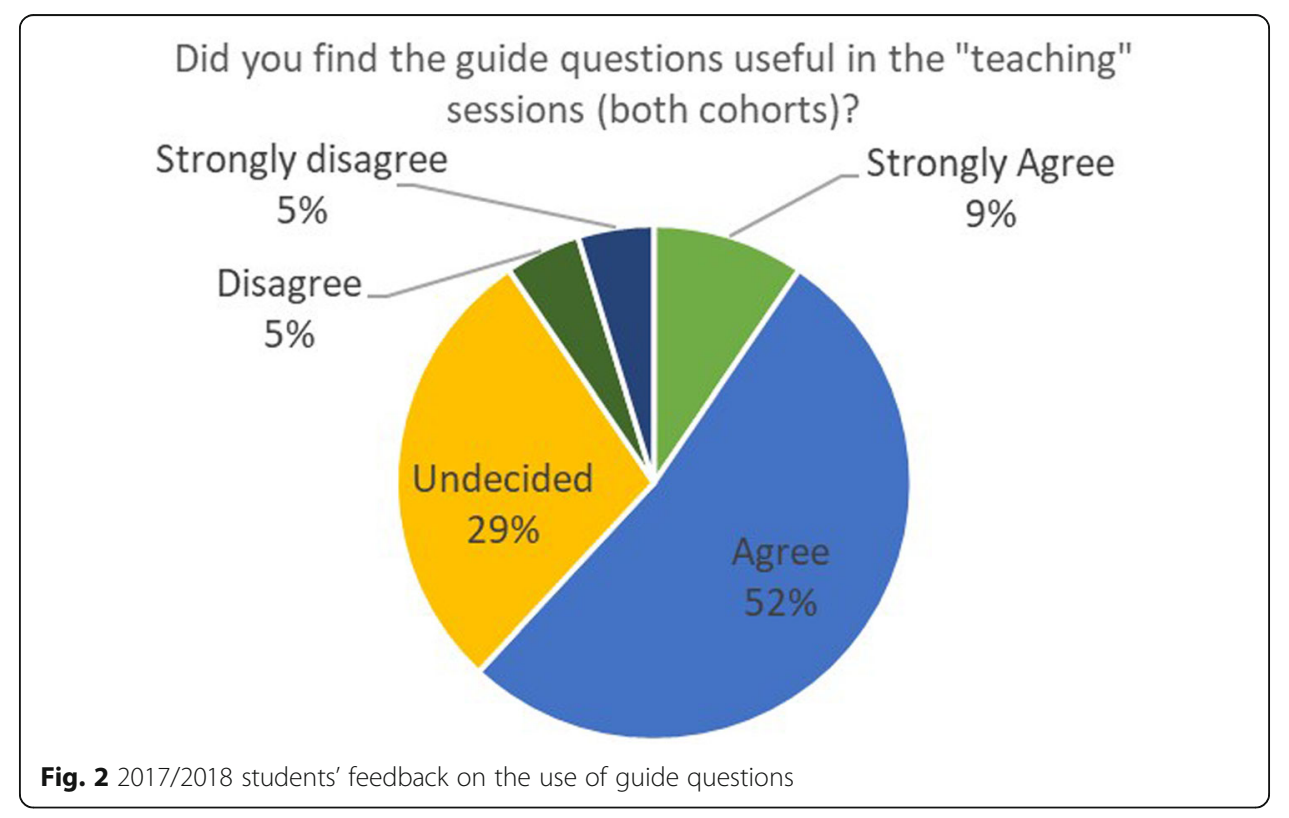




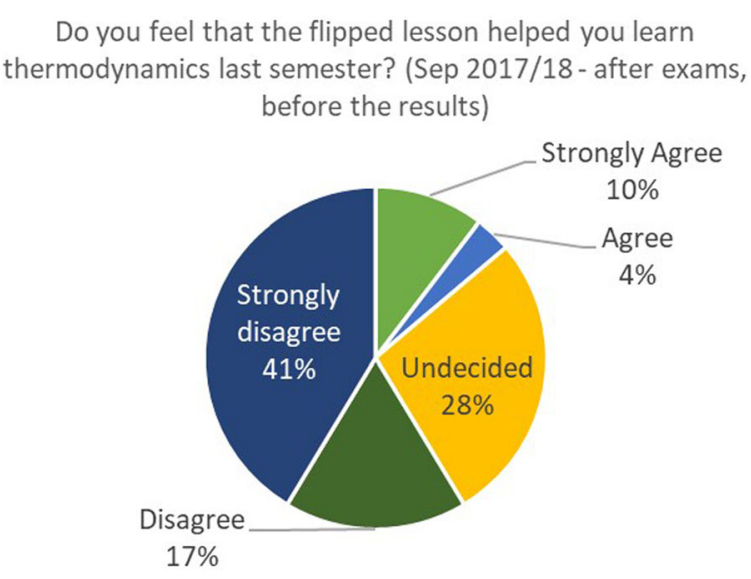

Fig. 3 September 2017/2018 students' feedback on the flipped lesson

In their written comments on what they gained from the sessions, the students were generally positive, again providing comments in line with expectations. They enjoyed using the materials and being able to determine whether they understood the topic on their own. They enjoyed working with their classmates in the class activities and being able to participate in the lessons, emphasising the active nature of the lesson structure.

Concerning their exam results, 40 out of the 45 students from the September cohort did well (scoring 50\% and above) in this topic. All 45 students passed the exam (scored above $40 \%$ ). Five students did not attempt the 2 questions on this topic. For the January cohort, 25 out of the 27 students did well in this topic and 23 students passed the exam. All the students in this cohort attempted the 2 questions on this topic, with only 2 having no marks. Again, more positive outcomes, highlighting the successful implementation of this pedagogic style.

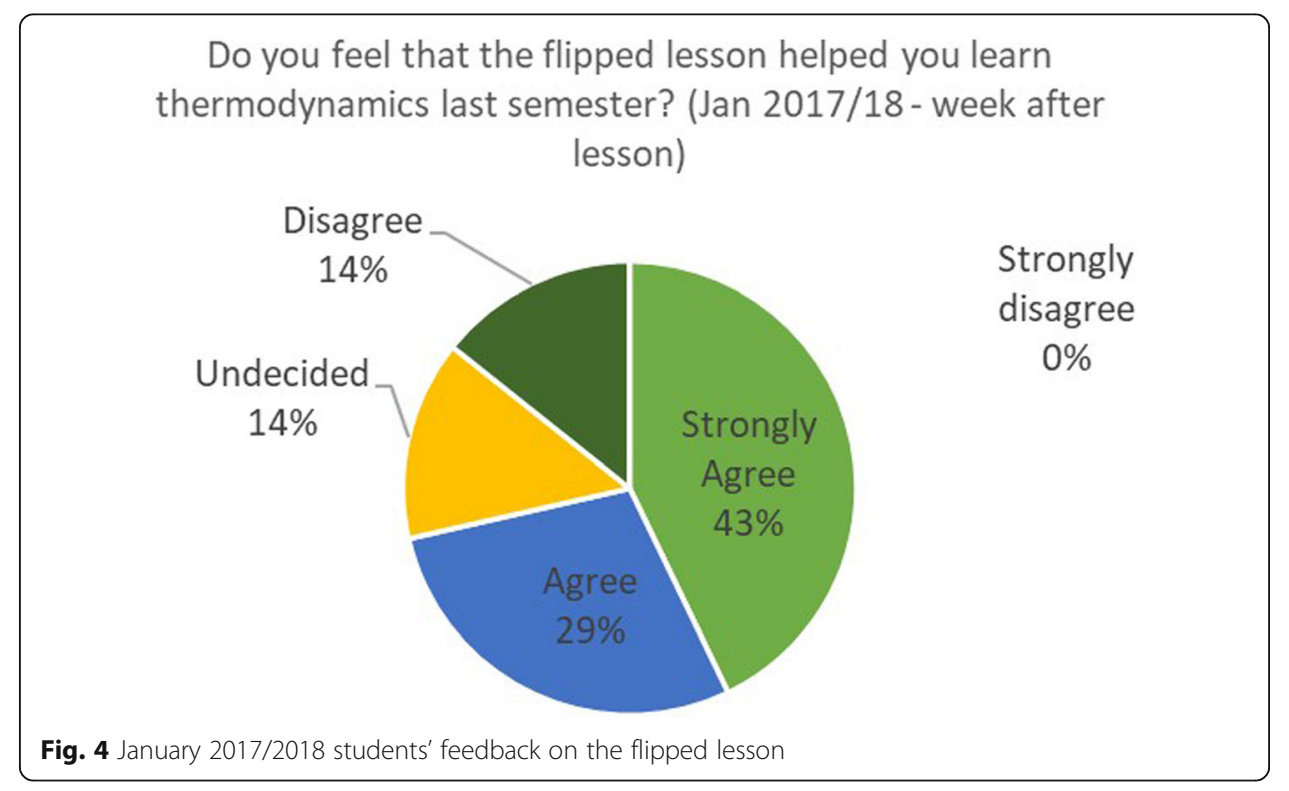




\section{Discussion}

As this is a small-scale use of a known pedagogical style, it is necessary to carry out a critical review of the process used and provide possible amendments. It is an opportunity to reflect on my delivery and decide what significant changes can be made to it, particularly with respect to threshold concepts. The key issues I had to deal with are those commonly encountered by those taking on a flipped session-initial dislike by students, non-participation and time to prepare (Simonson, 2017). The sessions did take some time to create and structure, particularly the interactive videos. However, the need for a change in student outcomes was a key motivator in preparing the material.

I realised that the initial dislike and non-participation is to be expected in this type of learning environment. Simonson (Simonson, 2017) stated that some students may see it as a heavier workload. They may lack the motivation to do work in or out of the classroom if they do not feel competent. In addition, the survey results show that the students' perspective on their learning journey can be quite inconsistent-they seem to feel confident soon after the lesson, but that confidence fades after they sit the exam. This may be as expected, but there remains a need to ensure that they are aware of the journey they are undertaking, so are prepared for it. Hence, they are more likely to take part in the flipped lesson (Khoo et al., 2018).

Therefore, an initial step in any flipped lesson is to allow the students to voice their concerns and any expectations they have about the flipped lesson. This can be achieved by providing a more detailed introduction at the start of the session (Balan, Clark, \& Restall, 2015). Balan et al. (Balan et al., 2015) found that this helped to develop a positive learning culture among the students, as they understood the need for pre-learning and active engagement.

At various points in the semester, I used surveys for the three cohorts to ascertain whether the sessions were enjoyable and effective. This was not extensive enough to discover whether deep learning had taken place. Therefore, surveys and/or structured interviews/focus groups would be required during and after the flipped session to assess if deep learning has taken place. It would help to ascertain whether the students understand they are on a journey and the possible routes that journey may take.

The flipped lesson can be further enhanced by allowing students to be an active part of the process. This was shown in a study undertaken by the School of Veterinary Studies at the University of Edinburgh. The students were given the freedom to choose their preferred resources and create materials on troublesome topics they had identified (Argyle, Hahn, Clarkson, Paterson, \& Rhind, 2015). These resources were shared with fellow students, in addition to the resources provided by the lecturer/academic of that module. This meant there was a plethora of resources from which each student could choose. While this felt like overloading to some of the students, a fair number did use the resources. The students also provided invaluable feedback on which resources worked well for them. Interestingly, student-narrated videos were the most popular resource.

Again, this highlights the need for a media that is more interactive than simply reading a webpage or PowerPoint notes. Overall, there was an appreciation for the time and effort academics put in to develop materials dealing with troublesome knowledge. Among students, there was a greater awareness of the need to invest time to understand new materials. This process takes student review into account. This has been 
identified as an approach faculty may utilise to help students with threshold concepts (Rhem, 2013). This was something I tried to accomplish with the use of guide questions, then publishing the students' answers.

All three cohorts were unanimous in their requests for more videos, having enjoyed using them. The questions used in the videos covered the various learning outcomes for the topic, so students were able to test their learning. The students' perspectives on the use of these videos during the flipped lesson are shown in Figs. 5 and 6 (similar results for both 2017/ 2018 cohorts meant an average for the whole year could be taken in the survey results).

Figures 5 and 6 also show that interactive videos, ideally, should be placed in context by having an activity session for the students to be able to apply their knowledge.

\section{Proposed learning format}

"The emphasis is on the organisation and good implementation of the flipped classroom in order to attain the real effects of flipped learning" (Hwang et al., 2015). This

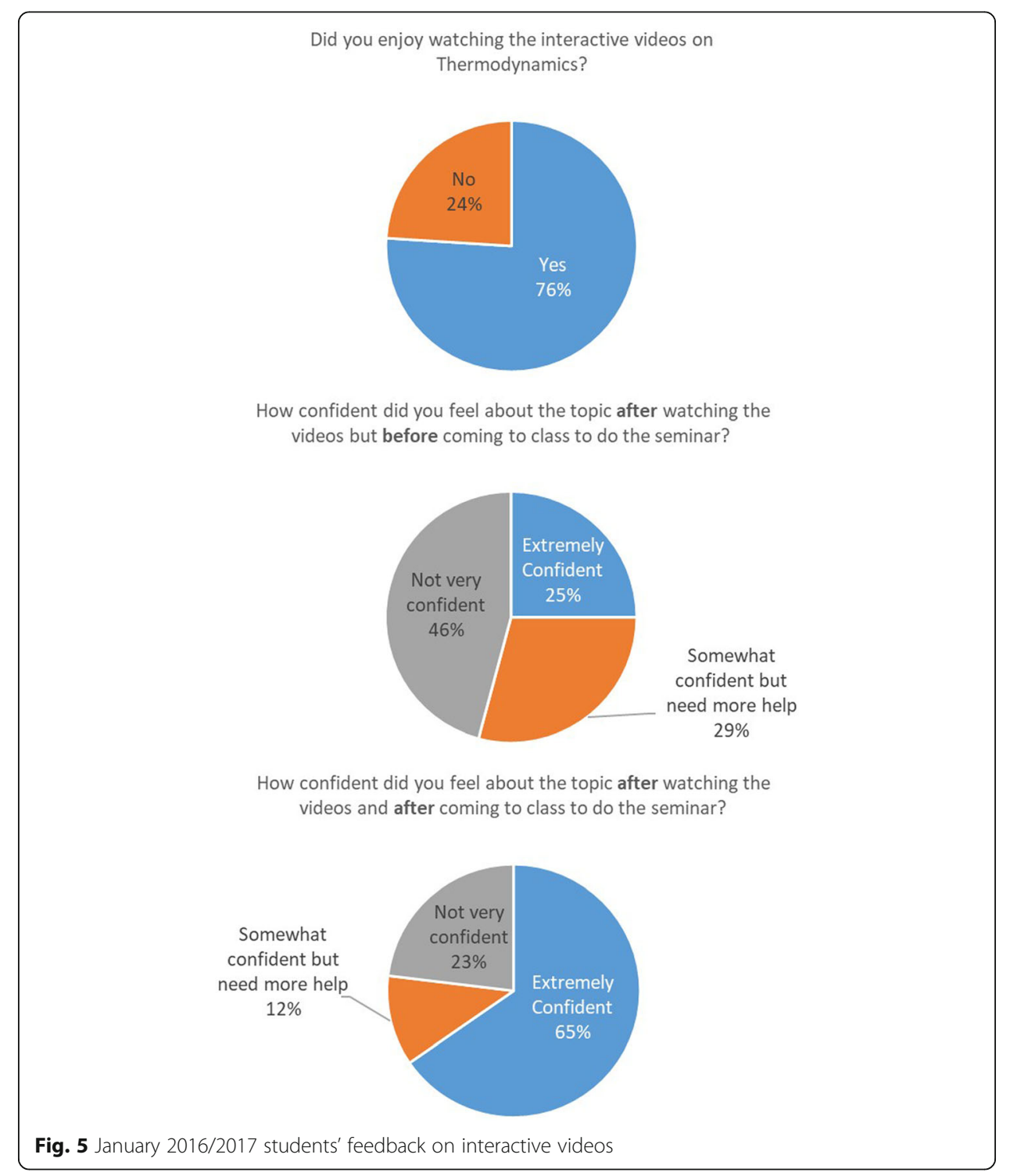


Did you enjoy watching the interactive videos on thermodynamics?

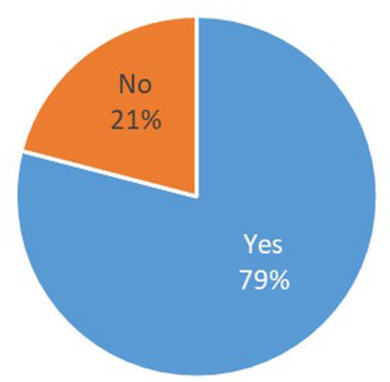

How confident did you feel about the topic after watching the videos but before coming to class to do the seminar?

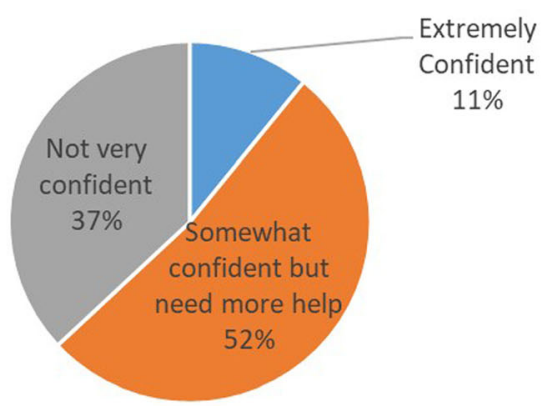

How confident did you feel about the topic after watching the videos and after coming to class to do the seminar?

Not very confident $16 \%$

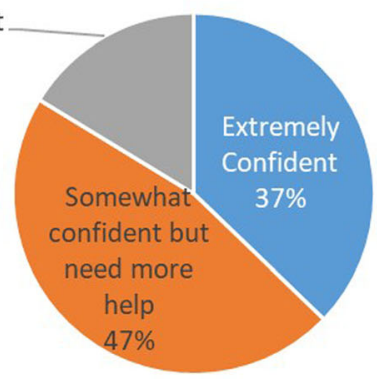

Fig. 6 September and January 2017/2018 students' feedback on interactive videos

has led me to propose a new format for the flipped lesson, particularly one that will help overcome threshold concepts:

1. Test before the session (in-class or online). The answers should not be shared. The students (and tutor) will make a note of the scores to be compared at the end of the flipped session.

2. Explore the topic with a discussion question. This should expose current/prevalent thinking. It will prepare the students for the lesson and provide them with the competency they need to undertake the flipped activities.

3. The format for the rest of the session is shown in Table 1.

4. Repeat the test and then share the answers as part of a group discussion exercise. 
Table 1 Proposed flipped learning format for activities at home and in class

\begin{tabular}{ll}
\hline Before class & In class \\
\hline Videos, slide notes, and other reading materials & $\begin{array}{l}\text { Review answers to guide questions } \\
\text { and answer any questions }\end{array}$ \\
$\begin{array}{l}\text { Guide questions: answers posted on Padlet, } \\
\text { for example, or shared as a comic strip or }\end{array}$ & $\begin{array}{l}\text { Carry out group activities—worksheets, } \\
\text { infographics, etc. }\end{array}$ \\
game/problem-based learning \\
(Self-assessment is the aim) & (Peer and teacher assessment are essential here) \\
\hline
\end{tabular}

Active learning tasks carried out in class will enable students to achieve higher-order learning skills, such as synthesis and application. Having the test at the start and at the end of the session(s) helps the student further assess what they have learned, encouraging better self-efficacy (make every improvement a win).

It should be noted that this is not a proposal for a "one-size-fits-all" approach to a well-known pedagogical format. It is a valid starting point to help academics provide their students with the tools they need in order to cross the threshold. The learning goals identified in the "Case description" section, in combination with the proposed format, may be seen as seeking to help students develop a love for learning, a valid basis for overcoming any threshold concept, hence doing well in a chosen programme.

\section{Conclusion}

The flipped classroom can be a very effective tool in overcoming threshold concepts. Being an uncomfortable process implies students do need time: time to understand and, where necessary, time to review their ability/skills. Therefore, time and effort are needed to make a cohesive and very effective flipped classroom, enabling students to make the most of the resources available to them. This would, in turn, provide an increase in self-efficacy. This is invaluable when it comes to understanding the threshold concept.

The study provided here relates to the topic of thermodynamics as part of a physics module on a foundation year programme. The final exam question results show improvements in student understanding. The overall exam scores show improvements in students' study skills. The latter may be due to the use of this process for a threshold concept. This then influenced how the students studied for the rest of the module.

There is a need to ensure the students are aware of their learning journey, so they can make the most of the learning process. The students' feedback shows that they still require a person to be involved with their learning. Hence, when taking on the flipped classroom, there is a need for a more involved approach by tutors (as a true guide would do).

The emphasis is on providing an avenue for self-assessment at home (via interactive videos, for example) and peer assessment in class. In addition, sharing with students what exactly is expected of them, as well as why the flipped classroom format is being used, may increase their willingness to participate and learn with a flipped approach (Khoo et al., 2018; Simonson, 2017). Then again, as Simonson (Simonson, 2017) explained, this would depend on the course and the concept being covered, as the aim is a truly learner-centred environment. In that vein, the flipped classroom format proposed in this paper, even though specifically developed for a threshold concept in physics, can be applied to any course/topic and may be adapted as required. 
Abbreviations

HE: Higher education; PGCert (HE): Postgraduate Certificate in Higher Education

\section{Acknowledgements}

The authors would like to acknowledge the participation of her students in this study.

\section{Author's contributions}

I am the sole author of the paper and responsible for its final contents. The author read and approved the final manuscript.

\section{Author's information}

Dr. Nkaepe Esoetok Etteh Olaniyi, BEng (Hons), PhD, FHEA, CMALT, is currently the Head of Computing at Kaplan Open Learning.

\section{Funding}

This research did not receive any specific grant from funding agencies in the public, commercial, or not-for-profit sectors.

\section{Availability of data and materials}

Data supporting the findings of this study are available from the author on request. Please note that this is a collation of anonymised results.

\section{Competing interests}

The author declares that there are no competing interests.

Received: 7 January 2019 Accepted: 5 January 2020

Published online: 29 January 2020

\section{References}

Anderson, L., Krathwohl, D., Airasian, P., Cruikshank, K., Mayer, R., Pintrich, P. R., Raths, J., \& Wittrock, M. (2001). A taxonomy for learning, teaching, and assessing: A revision of Bloom's Taxonomy of Educational Objectives. New York: Pearson, Allyn \& Bacon.

Argyle, S., Hahn, C., Clarkson, E., Paterson, J., \& Rhind, S. (2015). Co-development of a flipped learning strategy. https://www. ed.ac.uk/institute-academic-development/learning-teaching/funding/funding/forum/2015.

Bajada, C., Jarvis, W., Trayler, R., \& Bui, A. (2016). Threshold concepts in business school curriculum - A pedagogy for public trust. Education and Training., 58(5), 540-563.

Balan, P., Clark, M., \& Restall, G. (2015). Preparing students for flipped or team-based learning methods. Education and Training., 57(6), 639-657.

Bates, S., \& Galloway, R. (2012). The inverted classroom in a large enrolment introductory physics course: A case study. In HEA STEM learning and teaching conference. https://www2.ph.ed.ac.uk/ rgallowa/Bates_Galloway.pdf.

Bergmann, J., \& Sams, A. (2012). Flip your classroom: Reach every student in every class every day. Eugene, Or: International Society for Technology in Education.

Bialik, M. \& Fadel, C. (2015). Meta-learning for the $21^{\text {st }}$ century: What should students learn? Center for Curriculum Redesign. https://curriculumredesign.org/wp-content/uploads/CCR-Meta-Learning-FINAL-Nov-17-2015.pdf.

Biggs, J., \& Tang, C. (2011). Teaching for quality learning at university. What the student does (4th ed.). Maidenhead: Society for Research into Higher Education \& Open University Press.

Chandler-Grevatt, A. (2015). Challenging concepts in chemistry. Education in Chemistry. https://eic.rsc.org/feature/challengingconcepts-in-chemistry/2000069.article.

Clarke, D. (2010). Don't lecture me! In 2010 Conference of the Association for Learning Technology (ALT). https://www. youtube.com/watch?v=9e4iFx2Gm0A.

Cousin, G. (2006). An introduction to threshold concepts. Planet. 17(1), 4-5 (2006). https://doi.org/10.11120/plan.2006. 00170004.

Danker, B. (2015). Using flipped classroom approach to explore deep learning in large classrooms. Practice and Evidence of Scholarship of Teaching and Learning in Higher Education, Special Issue: Threshold Concepts and Conceptual Difficulty., 3(1), 171-186.

Descombe, M. (2014). The good research guide: for small-scale social research projects. 5th ed. Maidenhead: Open University Press.

Flanagan, M. (2017). Threshold concepts: Undergraduate teaching, postgraduate training and professional development. A short introduction and bibliography. https://www.ee.ucl.ac.uk/ mflanaga/thresholds.html.

Freeman, S., Eddy, S., McDonough, M., Smith, M., Okoroafor, N., Jordt, H., \& Wenderoth, M. (2014). Active learning increases student performance in science, engineering and mathematics. Proceedings of the National Academy of Sciences of the United States of America. 111(23), 8410-8415 (2014). https://doi.org/10.1073/pnas.1319030111.

Galster, M., Mitrovic, A., \& Gordon, M. (2018). Toward enhancing the training of software engineering students and professionals using active video watching. In 2018 IEEE/ACM 40th International Conference on Software Engineering: Software Engineering Education and Training (ICSE-SEET) (pp. 5-8). Gothenburg: IEEE. https://doi.org/10.1145/3183377. 3183384.

Guvenc, G. (2018). The flipped classroom approach in teaching writing: An action research. International Journal of Social Sciences and Education Research, 4(3), 421-432.

Hung, H. (2015). Flipping the classroom for English language learners to foster active learning. Computer Assisted Language Learning., 28(1), 81-96. https://doi.org/10.1080/09588221.2014.967701. 
Hwang, GJ., Lai, CL., \& Wang, SY. (2015). Seamless flipped learning: A mobile technology-enhanced flipped classroom with effective learning strategies. Journal of Computers in Education. 2: 449 (2015). https://doi.org/10.1007/s40692-015-0043-0.

Jisc. (2010). Effective assessment in a digital age: A guide to technology-enhanced assessment and feedback. https:// facultyinnovate.utexas.edu/sites/default/files/digiassass_eada.pdf.

Khoo, E., Peter, M., Scott, J., \& Round, H. (2018). Flipped classroom learning in a first-year undergraduate engineering course. In T. Bastiens et al. (Eds.), Proceedings of EdMedia: World Conference on Educational Media and Technology (pp. 1275-1280). Amsterdam: Association for the Advancement of Computing in Education (AACE).

Kinchin, I. (2010). Solving Cordelia's Dilemma: Threshold concepts within a punctuated model of learning. Journal of Biological Education. 44(2), 53-57 (2010). https://doi.org/10.1080/00219266.2010.9656194.

King, A. (1993). From sage on the stage to guide on the side. College Teaching., 41(1), 30-35.

Kirschner, P., Sweller, J., \& Clark, R. (2015). Why minimal guidance during instruction does not work: An analysis of the failure of constructivist, discovery, problem-based, experiential, and inquiry-based teaching. Educational Psychologist., $41(2), 75-86$.

Kouloumbaritsi, A., Dimitroglou, E., Mavrikaki, E., \& Galanopoulou, D. (2013). Action research on using flipped classroom principles to teach upper high school biology. Paper presented at the 7th International Conference in Open and Distance Learning, Athens, Greece. https://www.researchgate.net/publication/304578146_Action_Research_on_Using_ Flipped_Classroom_Principles_to_Teach_Upper_High_School_Biology.

Langbauer, M., \& Lehner, F. (2015). An interactive video system for learning and knowledge management. In 2015 International Conference on Enterprise Systems (ES) (pp. 55-56). Basel: IEEE.

Mayer, R. (2014). Research-based principles for multimedia learning. Talk at HILT's Scholar to Practitioner Speaker Series. Harvard University. 5 May 2014. Online video. http://www.youtube.com/watch?v=AJ3wSf-ccXo.

Meyer, J., \& Land, R. (2003). Threshold concepts and troublesome knowledge: linkages to ways of thinking and practising within the Disciplines ETL Project. http://www.etl.tla.ed.ac.uk/docs/ETLreport4.pdf.

Meyer, J., \& Land, R. (2006). Overcoming barriers to student understanding: Threshold concepts and troublesome knowledge. London: Routledge.

Mezirow, J. (1991). Transformative dimensions of adult learning. San Francisco: Jossey-Bass.

Milman, N. B. (2012). The flipped classroom strategy: What is it and how can it best be used? Distance Learning., 9, 85-87.

Moffett, J. (2015). Twelve tips for "flipping" the classroom. Medical Teacher., 37, 331-336. https://doi.org/10.3109/0142159X 2014.943710

Nouri, J. (2016). The flipped classroom: For active, effective and increased learning - especially for low achievers. International Journal of Educational Technology in Higher Education, 13, 33. https://doi.org/10.1186/s41239-016-0032-z.

O'Donnell, R. M. (2015). Threshold concepts and their relevance to economics. In ATEC 2009: 14th Annual Australasian Teaching, Economics Conference (pp. 190-200). Brisbane: School of Economics and Finance, Queensland University of Technology.

Rhem, J. (2013). Before and after students "get it": Threshold concepts. Online. https://teachingcommons.stanford.edu/ teaching-talk/and-after-students-get-it-threshold-concepts.

Schmidt, H., Wagener, S., Smeets, G., Keemink, L., \& van der Molen, H. (2015). On the use and misuse of lectures in higher education. Health Professions Education. 1(1), 12-18 (2015). https://doi.org/10.1016/j.hpe.2015.11.010.

Serbanescu, R. (2017). Identifying threshold concepts in physics: Too many to count! Practice and Evidence of Scholarship of Teaching and Learning in Higher Education, Special Issue: Threshold Concepts and Conceptual Diffculty. 12(2): 378-396.

Simonson, S.R. (2017). To flip or not to flip: What are the questions? Education Sciences.7(3), 71 (2017). https://doi.org/10. 3390/educsci7030071.

Sun, X. (2017). An action research study from implementing flipped classroom model in professional English teaching and learning. 3rd Annual International Conference on Social Science and Contemporary Humanity Development (SSCHD 2017). Atlantis Press. https://doi.org/10.2991/sschd-17.2017.63

Timmermans, T., \& Meyer, J. (2017). A framework for working with university teachers to create and embed 'Integrated Threshold Concept Knowledge' (ITCK) in their practice. International Journal for Academic Development. https://doi.org/10. 1080/1360144X.2017.1388241.

University of Plymouth. (2014). 7 steps to a flipped classroom. University of Plymouth: Educational Development Teaching and Learning. Online resource. https://www.plymouth.ac.uk/uploads/production/document/path/2/2399/7_Steps_to_a_ Flipped_Classroom.pdf.

University of Toronto. (2019). Flipped classrooms - Benefits and challenges. Online Resource. https://guides.library.utoronto. ca/c.php?g=448614\&p=3552449.

\section{Publisher's Note}

Springer Nature remains neutral with regard to jurisdictional claims in published maps and institutional affiliations. 